\title{
ANALISIS INDEKS KPUASAN MASYARAKAT PADA PUSAT KESEHATAN MASYARAKAT SUNGAI LILIN KABUPATEN MUSI BANYUASIN
}

\author{
Oleh : \\ Usailan Oemar \\ Dosen Fakultas Ekonomi STIE Rahmaniyah, Sekayu \\ Email : elanoemar11@yahoo.com
}

\begin{abstract}
Abstrak
Tujuan penelitian ini adalah untuk mengetahui Indeks Kepuasan Masyarakat (IKM) terhadap pelayanan di Puskesmas Sungai Lilin Kecamatan Sungai Lilin Kabupaten Musi Banyuasin yang diukur dengan 14 indikator Indeks Kepuasan Masyarakat mengacu pada KepMen PAN No: KEP/25/M.PAN/2/2004 tentang Pedoman Penyusunan IKM Unit Pelayanan Instansi Pemerintah termasuk BUMN/BUMD. Sampel dalam penelitian ini sebanyak 140 responden. Jenis data yang digunakan adalah data primer yang dilakukan melaui wawancara dan penyebaran kuesioner. Metode analisis data menggunakan Uji Validitas, Uji Reliabilitas, dan Analisis Indeks Kepuasan Masyarakat. Hasil analisis Indeks Kepuasan Masyarakat, Nilai Indeks yang diperoleh sebesar 2,73 dan Nilai IKM sebesar 68,25. Hal ini berarti bahwa mutu/kualitas yang dilakukan oleh Puskesmas Sungai Lilin termasuk kategori B, sehingga kinerja pelayanannya dapat dikatakan baik. Dilihat dari nilai per unsur pelayanan, prosedur pelayanan merupakan unsur dengan indeks tertinggi dengan nilai IKM sebesar 78,5 berada pada tingkat mutu baik, dan kategori kinerja baik, sedangkan unsur dengan indeks terendah yaitu unsur kepastian jadwal pelayanan dengan nilai IKM sebesar 47,75 berada pada tingkat mutu baik, dan kategori kinerja baik.

Kesimpulan hasil penelitian menunjukkan bahwa pelayanan kesehatan yang diberikan oleh Puskesmas Sungai Lilin yang diukur dengan indikator indeks kepuasan masyarakat telah dilaksanakan dengan baik.
\end{abstract}

Kata Kunci : Indeks Kepuasan Masyarakat, Pelayanan

\section{PENDAHULUAN}

\subsection{Latar Belakang Masalah}

Salah satu kegiatan yang dilakukan oleh sebuah organisasi adalah memberikan pelayanan baik kepada unit-unit kegiatan di dalam organisasi maupun kepada pihak di luar organisasi. Aktivitas pelayan sangat berpengaruh terhadap pencapaian mutu dan kelancaran kegiatan organisasi serta berpengaruh terhadap pencapaian tujuan organisasi secara keseluruhan.

Organisasi publik dalam memberikan pelayanan yang baik dituntut untuk dapat bertindak cepat dan akurat. Hal tersebut merupakan sebuah kewajiban yang harus dilakukan. Bagi organisasi publik, pelayanan yang baik tercermin dari setiap efektivitas dan efisiensi kegiatan yang dilakukan dengan lancar. Semakin cepat dan akurat pelayanan yang diberikan maka kualitas pelayanan kan semakin baik.

Pemerintah mempunyai peranan penting untuk menyediakan layanan publik sesuai yang telah diamanatkan dalam Undang-undang. Undang-undang Nomor 25 Tahun 2009 tentang pelayanan publik pasal 1 menyebutkan bahwa "Pelayanan publik adalah kegiatan atau rangkaian kegiatan dalam rangka pemenuhan kebutuhan pelayanan sesuai dengan peraturan perundang-undangan bagi setiap warga negara dan penduduk atas barang, 
jasa dan/atau pelayanan administratif yang disediakan oleh penyelenggara pelayanan publik"

Salah satu pelayanan publik yang dilakukan aparatur pemerintah yaitu pelayanan masyarakat dibidang kesehatan.

Penyelenggaraan pelayanan kesehatan untuk masyarakat ditingkat dasar di Indonesia malaui Pusat Kesehatan masyarakat (Puskesmas) yang merupakan unit organisasi fungsional Dinas Kesehatan Kabupaten/Kotamadya dan diberi tanggung jawab sebgai pengelola kesehatan bagi masyarakat tiap wilayah kecamatan dari kabupaten/kotamadya.

Puskesmas Sungai Lilin Kecamatan S Lilin adalah salah satu Pusat Kesehatan Masyarakat yang ditunjuk pemerintah untuk melayani kesehatan di wilayah Sungai Lilin dan sekitarnya. Adanya bentuk pelayanan kesehatan yang diberikan oleh Puskesmas ini maka diharapkan pasien akan dapat memberikan penilaian terhadap Puskesmas Sungai Lilin, karena tidak bisa dipungkiri bahwa pelayanan Puskesmas seringkali mendapatkan banyak complain dari pasiennya. Sebagai upaya perbaikan pelayanan perlu dilakukan pengkajian tentang kualitas pelayanan Puskesmas Sungai Lilin melalui Indeks Kepuasan Masyarakat (IKM).

Untuk meningkatkan pelayanan masyarakat kepada masyarakat dan perbaikan organisasi secara terus menerus berupa peningkatan mutu, produktivitas, atau efisiensi maka pihak Pusat Kesehatan Masyarakat Sungai Lilin Kabupaten Musi Banyuasin berusaha untuk memperbaiki sitem manajemen yang ada dengan menerapkan KepMen PAN No: KEP/25/M/PAN/2/2004 yang mengharuskan organisasi-organisasi pemerintah melakukan pengukuran terhadap kepusasan masyarakat yang berfungsi untuk peningkatan mutu, produktivitas, atau efiseinsi. Berdasarkan kondisi tersebut di atas maka penulis tertarik untuk melakukan pengkajian dengan " Menganalisis Indeks Kepuasan Masyarakat pada Pusat Kesehatan Masyarakat Sungai Lilin Kecamatan Sungai Lilin Kabupaten Musi Banyuasin

\subsection{Rumusan Masalah}

Berdasarkan latar belakang di atas maka masalah dalam penelitian ini adalah: bagaimana indeks kepuasan masyarakat pada Pusat Kesehatan Masyarakat Sungai Lilin Kabupaten Musi Banyuasin?

\subsection{Tujuan Penelitian}

Tujuan dari penelitian ini adalah: untuk mengetahui dan menganalisis indeks kepuasan masyarakat pada Pusat Kesehatan Masyarakat Sungai Lilin Kabupaten Musi Banyuasin

\section{Tinjauan Pustaka}

\subsection{Kepuasan Masyarakat}

\subsubsection{Pengertian Kepuasan}

Kepuasan adalah suatu keadaan yang dirasakan konsumen setelah dia mengalami suatu kinerja (atau hasil) yang telah memenuhi berbagai harapannya. Arief (2007:35), kepuasan masyarakat merupakan faktor yang sangat penting dan menentukan keberhasilan suatu badan usaha karena masyarakat adalah konsumen dari produk yang dihasilkannya.

Menurut Definisi kepuasan masyarakat menurut Mowen dalam Arief (2007:36), Costumers satisfaction is defined as the overall attitudes regarding goods or services after its acquisition and uses. Oleh karena itu, badan usaha harus dapat memenuhi kebutuhan dan keinginan masyarakat sehingga mencapai kepuasan 
masyarakat dan lebih jauh lagi kedepannya dapat dicapai kesetiaan masyarakat.

Sebab, bila tidak dapat memenuhi kebutuhan dan kepuasan masyarakat sehingga menyebabkan ketidakpuasan masyarakat mengakibatkan kesetiaan masyarakat akan suatu produk menjadi luntur dan beralih ke produk atau layanan yang disediakan oleh badan usaha yang lain.

Menurut Mendelsohn dalam Arief (2007:45), ada 2 keuntungan bagi badan usaha dengan adanya kepuasan masyarakat yaitu first, retaining customers is less expensive than acquiring new ones. Second, increasing competition in the form of product, organizations, and distributing outlets means fierce pressure for costumers. And costumners satisfaction is viable strategy to maintain market share against the competitions.

Untuk mengukur kepuasan masyarakat digunakan atribut yang berisi tentang bagaimana masyarakat menilai suatu produk atau layanan yang ditinjau dari sudut pandang pelanggan. Menurut Dulka dalam Arief (2007:49), kepuasan masyarakat dapat diukur melalui atributatribut pembentuk kepuasan yang terdiri atas :

1. Value to price relationship. Hubungan antara harga yang ditetapkan oleh badan usaha untuk dibayar dengan nilai/manfaat yang diperoleh masyarakat.

2. Product value adalah penilaian dari kualitas produk atau layanan yang dihasilkan suatu badan usaha.

3. Product benefit adalah manfaat yang diperoleh masyarakat dari mengkosumsi produk yang dihasilkan oleh badan usaha.

4. Product feature adalah ciri-ciri atau karakteristik tertentu yang mendukung fungsi dasar dari suatu produk sehingga berbeda dengan produk yang ditawarkan pesaing.

5. Product design adalah proses untuk merancang tampilan dan fungsi produk.

6. Product reliability and consistency adalah kekakuratan dan keandalan produk yang dihasilkan oleh suatu badan usaha.

7. Range of product ar services adalah macam dari produk atau layanan yang ditawarkan oleh suatu badan usaha.

\subsubsection{Indeks Kepuasan Masyarakat (IKM)}

Menurut Keputusan Menteri Pemberdayaan Aparatur Negara Nomor: 63/KEP/M.PAN/7/2003 tentang tentang Pedoman Umum Penyelenggaraan Pelayanan Publik, Indeks Kepuasan Masyarakat (IKM) adalah Data informasi tentang tingkat kepuasan masyarakat yang diperoleh dari hasil pengukuran secara kuantitatif dan kualitatif atas pendapat masyarakat dalam memperoleh pelayanan dari aparatur penyelenggara pelayanan publik dengan membandingkan antara harapan dan kebutuhannya.

Penyelenggara pelayanan publik adalah setiap institusi penyelenggara negara, korporasi, lembaga independen yang dibentuk berdasarkan undang-undang untuk kegiatan pelayanan publik, dan badan hukum lain yang dibentuk semata-mata untuk kegiatan pelayanan publik. Berdasarkan prinsip pelayanan sebagaimana telah ditetapkan dalam Keputusan Menteri Pemberdayaan Aparatur Negara Nomor: 63/KEP/M.PAN/7/2003 tentang tentang Pedoman Umum Penyelenggaraan Pelayanan Publik, yang kemudian dikembangkan menjadi 14 unsur yang 
"relevan, valid" dan "reliabel", sebagai unsur minimal yang harus ada untuk dasar pengukuran indeks kepuasan masyarakat adalah sebagai berikut:

1. Prosedur pelayanan, yaitu kemudahan tahapan pelayanan yang diberikan kepada masyarakat dilihat dari sisi kesederhanaan alur pelayanan.

2. Persyaratan Pelayanan, yaitu persyaratan teknis dan administratif yang diperlukan untuk mendapatkan pelayanan sesuai dengan jenis pelayanannya.

3. Kejelasan petugas pelayanan, yaitu keberadaan dan kepastian petugas yang memberikan pelayanan (nama, jabatan serta kewenangan dan tanggung jawabnya)

4. Kedisiplinan petugas pelayanan, yaitu kesungguhan petugas dalam memberikan pelayanan terutama terhadap konsistensi waktu kerja sesuai ketentuan yang berlaku.

5. Tanggung jawab petugas pelayanan, yaitu kejelasan wewenang dan tanggung jawab petugas dalam penyelenggaraan dan penyelesaian pelayanan.

6. Kemampuan petugas pelayanan, yaitu tingkat keahlian dan ketrampilan yang dimiliki petugas dalam memberikan/menyelesaikan pelayanan kepada masyarakat.

7. Kecepatan pelayanan, yaitu target waktu pelayanan dapat diselesaikan dalam waktu yang telah ditentukan oleh unit penyelenggara pelayanan.

8. Keadilan mendapatkan pelayanan, yaitu pelaksanaan pelayanan dengan tidak membedakan golongan/status masyarakat yang dilayani.

9. Kesopanan dan keramahan petugas, yaitu sikap dan perilaku petugas dalam memberikan pelayanan kepada masyarakat secara sopan dan ramah serta saling menghargai dan menghormati.

10. Kewajaran biaya pelayanan, yaitu keterjangkauan masyarakat terhadap besarnya biaya yang ditetapkan oleh unit pelayanan.

11. Kepastian biaya pelayanan, yaitu kesesuaian antara biaya yang dibayarkan dengan biaya yang telah ditetapkan.

12. Kepastian jadwal pelayanan, yaitu pelaksanaan waktu pelayanan, sesuai dengan ketentuan yang telah ditetapkan.

13. Kenyamanan lingkungan, yaitu kondisi sarana dan prasarana pelayanan yang bersih, rapi, dan teratur sehingga dapat memberikan rasa nyaman kepada penerima pelayanan.

14. Keamanan Pelayanan, yaitu terjaminnya tingkat keamanan lingkungan unit penyelenggara pelayanan ataupun sarana yang digunakan, sehingga masyarakat merasa tenang untuk mendapatkan pelayanan terhadap resiko-resiko yang diakibatkan dari pelaksanaan pelayanan.

Saladdin (2011: 53). Penelitian dari survey Indeks Kepuasan Masyarakat (IKM) Pada Badan Peizinan dan Penanaman Modal Kabupaten Ogan Komering Ilir. Hasil analisis terhadap nilai rata-rata per unsur pelayanan tahun 2010 menunjukkan bahwa unsur pelayanan"prosedur pelayanan" dan kesopanan dan keramahan petugas" merupakan unsur pelayanan dengan nilai tertinggi. Unsur pelayanan yang mempunyai nilai rat-rata terendah dari unsur pelayanan adalah : kepastian jadwal pelayanan dan kecepatan pelayanan.

Hardi Utomo (2015: 13). Penelitian Analisis Indeks Kepuasan Masyarakat Pada Pelayanan Publik Di Puskesmas Kalicacing 
Kota Salatiga. Hasil Penelitian IKM menunjukkan Puskesmas Kalicacing memiliki nilai indeks sebesar 3,27 dan nilai IKM sebesar 81,74 yang berarti mutu pelayanan masuk dalam katagori A, sehingga kinerja pelayanannya dapat dikatan sangat baik. Berdasarkan tingkat kesesuaian sebesar $92,17 \%$, pelayanan yang diberikan sudah sangat baik

\subsection{Penyusunan Indeks Kepuasan Masyarakat}

Menurut Keputusan Menteri Pemberdayaan Aparatur Negara KEP/63/KEP/M.PAN/7/2003, dalam penyusunan IKM digunakan kuesioner sebagai alat bantu pengumpulan data kepuasan masyarakat penerima pelayanan. Kuesioner disusun berdasarkan tujuan survei terhadap tingkat kepuasan masyarakat. Kuesioner dibagi atas 3 (tiga) bagian yaitu:

1. Identitas responden yang berguna untuk menganalisis profil responden dalam penilaiannya terhadap unit pelayanan instansi pemerintah.

2. Identitas pencacah yang merupakan admin

3. Mutu pelayanan publik adalah pendapat penerima pelayanan yang memuat kesimpulan atau pendapat responden terhadap unsur-unsur pelayanan yang dinilai.

\subsection{Pelayanan Publik}

Pelayanan adalah kegiatan yang dilakukan oleh seseorang atau sekelompok orang dengan landasan faktor material melalui sistem, prosedur dan metode tertentu dalam rangka usaha memenuhi kepentingan orang lain sesuai dengan haknya (Moenir: 2000:26-27). Pendapat lain menyebutkan bahwa pelayanan adalah suatu perbuatan (deed), suatu kinerja (performance) atau suatu usaha (effort), jadi menunjukkan secara inheren pentingnya penerima jasa pelayanan terlibat secara aktif di dalam produksi atau penyampaian proses pelayanan itu sendiri (Warella,1997:18)

Untuk kriteria penilaian kepuasan masyarakat menggunakan indikator sebagai berikut:

Tabel 1

Kriteria Penilaian Indeks Kepuasan Masyarakat

\begin{tabular}{|c|c|c|c|c|}
\hline $\begin{array}{c}\text { Nilai } \\
\text { Persepsi }\end{array}$ & $\begin{array}{c}\text { Nilai } \\
\text { Interval } \\
\text { IKM }\end{array}$ & $\begin{array}{c}\text { Nilai Interval } \\
\text { Konversi IKM }\end{array}$ & $\begin{array}{c}\text { Mutu } \\
\text { Pelayanan }\end{array}$ & $\begin{array}{c}\text { Kinerja Unit } \\
\text { Pelayanan }\end{array}$ \\
\hline & & & & \\
1 & $1,00-1,75$ & $25,00-43,75$ & $\mathrm{D}$ & Tidak baik \\
2 & $1,76-2,50$ & $43,76-62,50$ & $\mathrm{C}$ & Kurang baik \\
3 & $2,51-3,25$ & $62,51-81,25$ & $\mathrm{~B}$ & Baik \\
4 & $3,26-4,00$ & $81,26-100,00$ & $\mathrm{~A}$ & Sangat Baik \\
& \multicolumn{5}{|c|}{ Negara No.KEP/25/M.PAN/2/2004 } \\
\hline \multicolumn{5}{|c|}{ Sumber:Keputusan Menteri Pendayagunaan paratur }
\end{tabular}

\subsection{Kerangka Pemikiran}

Berdasarkan latar belakang masalah, rumusan masalah dan tujuan penelitian, maka penulis menyusun kerangka pemikiran sebagai berikut ini:

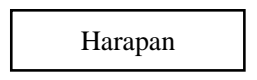


Kepuasan pelanggan (masyarakat) perasaan senang atau kecewa seseorang sebagai hasil dari perbandingan antara prestasi atau produk yang dirasakan dan yang diharapkannya. Selain itu kepuasan pelanggan merupakan perbandingan antara harapan dengan kenyataan. Untuk mengukur kepuasan terhadap pelayanan kesehatan yang diberikan oleh Pusat Kesehatan Masyarakat Sungai Lilin Kabupaten Musi Banyuasin akan digunakan indeks kepuasan masyarakat berdasarkan Keputusan Menteri Pendayagunaan Aparatur Negara No. Kep./25/M.PAN/2/2004 tentang Indeks Kepuasan Masyarakat, menyatakan bahwa: Indeks Kepuasan Masyarakat (IKM) adalah data dan informasi tentang tingkat kepuasan masyarakat yang diperoleh dari hasil pengukuran secara kuantitatif dan kualitatif atas pendapat masyarakat dalam memperoleh pelayanan dari aparatur penyelenggara palayanan publik dengan membandingkan anatar harapan dan kebutuhannya".

Kepuasan masyarakat dapat dilihat dari 14 indikator berdasarkan Kep./25/M.PAN/2/2004 yaitu: Prosedur Pelayanan, Persyaratan Pelayanan, Kejelasan petugas pelayanan, Kedisiplinan petugas pelayanan, Tanggungjawab petugas pelayanan, Kemampuan petugas pelayanan, Kecepatan pelayanan, Keadilan mendapatkan pelayanan, Kesopanan dan keramahan petugas, Kewajaran biaya pelayanan, Kepastian biaya pelayanan, Kepastian jadwal pelayanan, Kenyamanan lingkungan, Keamanan pelayanan.

\section{Metodologi Penelitian}

\subsection{Desain, Lokasi dan Waktu Penelitian}

Rancangan penelitian yang digunakan adalah penelitian eksplanasi (penjelasan) yaitu bagaimana variabel-variabel yang diteliti itu akan menjelaskan objek yang diteliti melalui data yang terkumpul dan pengamatan hanya dilakukan satu kali saja (Sugiyono:1999). Penelitian ini dilakukan pada Pusat Kesehatan Masyarakat S. Lilin Kabupaten Musi Banyuasin. Penelitian dilakukan pada bulan Juli 2016.

\subsection{Populasi dan Teknik Pengambilan Sampel}

Menurut Sugiyono (2004: 80), populasi adalah wilayah generalisasi yang terdiri atas: obyek/subyek yang mempunyai kualitas dan karakteristik tertentu yang ditetapkan oleh peneliti untuk dipelajari dan kemudian ditarik kesimpulannya. Adapun Populasi pada penelitian ini adalah masyarakat yang berobat pada Pusat Kesehatan Masyarakat S. Lilin. Menurut Sanusi (2011: 87) sampel adalah sekelompok kecil yang diamati dan merupakan bagian dari populasi sehingga sifat dan karekteristik populasi juga dimiliki oleh sampel.

Adapun teknik pengambilan sampel yang peneliti gunakan yaitu dengan menggunakan teknik accidental sampling, menurut Sugiyono (2010: 53) accidental sampling adalah teknik pengambilan sampel secara tidak sengaja atau secara acak, yaitu pasien yang berobat sebanyak 140 orang selama satu bulan pada Pusat Kesehatan Masyarakat Sungai Lilin Kabupaten Musi Banyuasin.

\subsection{Jenis dan Sumber data}

Menurut sumbernya, data yang digunakan adalah data primer dan data sekunder. Menurut Sugiyono (2009: 129), data primer adalah sumber data yang langsung memberikan data kepada pengumpul data, sedangkan data sekunder adalah sumber yang tidak langsung 
memberikan data kepada pengumpul data. Data primer dalam penelitian ini berupa hasil wawancara dan kuesioner, sedangkan data sekunder dalam penelitian ini berupa profil Pusat Kesehatan Masyarakat Sungai Lilin Kabupaten Musi Banyuasin, terdiri dari : karekteristik puskesmas, sumber daya manusia, fasilitas fisik, manajemen, pelayanan kesehatan dan kegiatan pemberdayaan masyarakat.

\subsection{Instrumen Penelitian}

Dalam penelitian ini peneliti memberikan kuesioner untuk mengumpulkan data. Kuesioner adalah instrumen pengumpulan data atau informasi yang dioperasionalkan ke dalam bentuk item atau pertanyaan. Penyusunan kuesioner dilakukan dengan harapan dapat mengetahui variabelvariabel apa saja yang menurut responden merupakan hal yang penting.

Tujuan penyusunan kuesioner adalah untuk memperbaiki bagian-bagian yang dianggap kurang tepat untuk diterapkan dalam pengambilan data terhadap responden. Yang menjadi dasar pembatasan menentukan variabel-variabel tersebut adalah harus dapat dimengerti dan dirasakan manfaatnya. Kuesioner dapat berfungsi sebagi alat dan sekaligus teknik pengumpulan data yang berisi sederet pertanyaan dalam wujud konkrit.

Dalam pengukuran variabel venelitian menggunakan instrumen penelitian dengan menggunakan skala likert yang mempunyai gradasi positif sampai dengan negatif dapat berupa katakata dengan pilihan sebagai berikut:

\section{Keterangan:}

Sangat Baik

Baik

Kurang Baik

Tidak Baik

\section{Pembahasan}

\subsection{Karakteristik Responden}

Penelitian ini menggunakan pendapat responden yang berjumlah 140 orang. Hasil pengisisan kuesioner oleh responden menunjukkan bahwa terdapat beberapa karakteristik mengenai responden antara lain berdasarkan: kelompok jenis kelamin, usia, pekerjaan.

Uraian tentang karakteristik responden berdasarkan jenis kelamin, usia, dan pekerjaan dapat dilihat pada Tabel 2 . dibawah ini.

Tabel 2

Distribusi Karakteristik Responden

\begin{tabular}{|c|c|c|c|c|}
\hline \multirow{2}{*}{ No. } & \multirow{2}{*}{$\begin{array}{l}\text { Identitas } \\
\text { Diri }\end{array}$} & \multirow{2}{*}{ Jenis Kelamin } & \multicolumn{2}{|c|}{ Jumlah } \\
\hline & & & Orang & $\%$ \\
\hline \multirow{3}{*}{1.} & \multirow{3}{*}{$\begin{array}{c}\text { Jenis } \\
\text { Kelamin }\end{array}$} & Laki-laki & 41 & 29 \\
\hline & & Perempuan & 99 & 71 \\
\hline & & Jumlah & 140 & 100 \\
\hline \multirow{4}{*}{2.} & \multirow{4}{*}{ Usia } & $>50$ Tahun & 14 & 10 \\
\hline & & $30-49$ Tahun & 56 & 40 \\
\hline & & $>20$ Tahun & 70 & 50 \\
\hline & & Jumlah & 140 & 100 \\
\hline \multirow{9}{*}{3.} & \multirow{9}{*}{ Pekerjaan } & Pelajar/mahasiswa & 6 & 4 \\
\hline & & Wirausaha/Swasta & 23 & 17 \\
\hline & & $\begin{array}{l}\text { Pegawai Negeri } \\
\text { Sipil }\end{array}$ & 62 & 44 \\
\hline & & Petani & 10 & 7 \\
\hline & & Guru & 9 & 6 \\
\hline & & Pedagang & 24 & 18 \\
\hline & & Ibu Rumah Tangga & 3 & 2 \\
\hline & & Lainnya & 3 & 2 \\
\hline & & Jumlah & 140 & 100 \\
\hline
\end{tabular}

Berdasarkan hasil pengisian kuesioner dari 140 responden merupakan masyarakat yang memeriksa kesehatan atau berobat pada Pusat Kesehatan Masyarakat Sungai Lilin Kabupaten Musi Banyuasin diketahui bahwa dari jenis kelaminnya 41 orang atau sekitar 29\% berjenis kelamin laki-laki sedangkan sisanya 99 orang atau sekitar $71 \%$ berjenis kelamin perempuan.

\subsection{Distribusi Jawaban Kuesioner}

Hasil jawaban 140 responden yang merupakan masyarakat Kecamatan Sungai Lilin Kabupaten Musi Banyuasin yang 
membutuhkan pelayanan kesehatan pada Pusat Kesehatan Masyarakat Sungai Lilin untuk pertanyaan yang berhubungan dengan indeks kepuasan masyarakat dapat dilihat dari tabel 3 dibawah ini.

Tabel 3.

Distribusi Jawaban Responden

Untuk Instrumen Indeks Kepuasan Masyarakat

Pusat Kesehatan Masyarakat S. Lilin

\begin{tabular}{|c|c|c|c|c|c|c|c|c|c|}
\hline \multirow{2}{*}{ No. } & \multirow{2}{*}{ Pernyataan } & \multicolumn{2}{|c|}{ TB } & \multicolumn{2}{|c|}{$\mathbf{K B}$} & \multicolumn{2}{|c|}{ B } & \multicolumn{2}{|c|}{ SB } \\
\hline & & $\mathbf{N}$ & $\%$ & $\mathbf{N}$ & $\%$ & $\mathbf{N}$ & $\%$ & $\mathbf{N}$ & $\%$ \\
\hline 1. & $\begin{array}{l}\text { Prosedur pelayanan, yaitu kemudahan tahapan } \\
\text { pelayanan yang diberikan kepada masyarakat dilihat } \\
\text { dari sisi kesederhanaan alur pelayanan. }\end{array}$ & 2 & 1,4 & 21 & 15 & 74 & 52,9 & 43 & 30,7 \\
\hline 2. & $\begin{array}{l}\text { Persyaratan pelayanan, yaitu persyaratan teknis dan } \\
\text { administratif yang diperlukan untuk mendapatkan } \\
\text { pelayanan sesuai dengan jenis pelayanannya. }\end{array}$ & 6 & 4,3 & 25 & 17,9 & 91 & 65,0 & 18 & 12,9 \\
\hline 3 & $\begin{array}{l}\text { Kejelasan petugas pelayanan, yaitu keberadaan dan } \\
\text { kepastian petugas yang memberikan pelayanan } \\
\text { (nama, jabatan serta kewenangan dan tanggung } \\
\text { jawabnya) }\end{array}$ & 8 & 5,7 & 43 & 30,7 & 71 & 50,7 & 18 & 12,9 \\
\hline 4 & $\begin{array}{l}\text { Kedisiplinan petugas pelayanan, yaitu kesungguhan } \\
\text { petugas dalam memberikan pelayanan terutama } \\
\text { terhadap konsistensi waktu kerja sesuai ketentuan } \\
\text { yang berlaku. }\end{array}$ & 9 & 6,4 & 46 & 32,9 & 66 & 47,1 & 19 & 13,9 \\
\hline 5 & $\begin{array}{l}\text { Tanggung jawab petugas pelayanan, yaitu kejelasan } \\
\text { wewenang dan tanggung jawab petugas dalam } \\
\text { penyelenggaraan dan penyelesaian pelayanan. }\end{array}$ & 6 & 4,3 & 28 & 20,0 & 69 & 49,3 & 37 & 26,4 \\
\hline 6 & $\begin{array}{l}\text { Kemampuan petugas pelayanan, yaitu tingkat } \\
\text { keahlian dan ketrampilan yang dimiliki petugas } \\
\text { dalam memberikan/menyelesaikan pelayanan } \\
\text { kepada masyarakat. }\end{array}$ & 6 & 4,3 & 30 & 21,4 & 79 & 56,4 & 25 & 17,9 \\
\hline 7 & $\begin{array}{l}\text { Kecepatan pelayanan, yaitu target waktu pelayanan } \\
\text { dapat diselesaikan dalam waktu yang telah } \\
\text { ditentukan oleh unit penyelenggara pelayanan. }\end{array}$ & 10 & 7,1 & 63 & 45,0 & 59 & 42,1 & 8 & 5,7 \\
\hline 8 & $\begin{array}{l}\text { Keadilan mendapatkan pelayanan, yaitu } \\
\text { pelaksanaan pelayanan dengan tidak membedakan } \\
\text { golongan/status masyarakat yang dilayani }\end{array}$ & 5 & 3,6 & 20 & 14,3 & 82 & 58,6 & 33 & 23,6 \\
\hline 9 & $\begin{array}{l}\text { Kesopanan dan keramahan petugas, yaitu sikap dan } \\
\text { perilaku petugas dalam memberikan pelayanan } \\
\text { kepada masyarakat secara sopan dan ramah serta } \\
\text { saling menghargai dan menghormati }\end{array}$ & 4 & 2,9 & 40 & 28,6 & 73 & 52,1 & 23 & 16,4 \\
\hline 10 & $\begin{array}{l}\text { Kewajaran biaya pelayanan, yaitu keterjangkauan } \\
\text { masyarakat terhadap besarnya biaya yang ditetapkan } \\
\text { oleh unit pelayanan }\end{array}$ & 10 & 7,1 & 38 & 27,1 & 73 & 52,1 & 19 & 13,6 \\
\hline 11 & $\begin{array}{l}\text { Kepastian biaya pelayanan, yaitu kesesuaian antara } \\
\text { biaya yang dibayarkan dengan biaya yang telah } \\
\text { ditetapkan. }\end{array}$ & 9 & 6,4 & 37 & 26,4 & 68 & 48,6 & 26 & 18,6 \\
\hline 12 & $\begin{array}{l}\text { Kepastian jadwal pelayanan, yaitu pelaksanaan } \\
\text { waktu pelayanan, sesuai dengan ketentuan yang } \\
\text { telah ditetapkan }\end{array}$ & 52 & 37,1 & 51 & 36,4 & 34 & 24,1 & 3 & 2,1 \\
\hline 13 & $\begin{array}{l}\text { Kenyamanan lingkungan, yaitu kondisi sarana dan } \\
\text { prasarana pelayanan yang bersih, rapi, dan teratur } \\
\text { sehingga dapat memberikan rasa nyaman kepada } \\
\text { penerima pelayanan }\end{array}$ & 9 & 6,4 & 29 & 20,7 & 80 & 57,1 & 22 & 15,7 \\
\hline 14 & $\begin{array}{l}\text { Keamanan Pelayanan, yaitu terjaminnya tingkat } \\
\text { keamanan lingkungan unit penyelenggara pelayanan } \\
\text { ataupun sarana yang digunakan, sehingga } \\
\text { masyarakat } \\
\text { merasa tenang untuk mendapatkan pelayanan } \\
\text { terhadap resiko-resiko yang diakibatkan dari } \\
\text { pelaksanaan } \\
\text { pelayanan. }\end{array}$ & 9 & 6,4 & 22 & 15,7 & 76 & 54,3 & 33 & 23,6 \\
\hline
\end{tabular}




\subsection{Metode Analisis Data}

Penelitian ini menggunakan beberapa metode untuk menganalisis data. Adapun metode analisis data yang digunakan adalah sebagai berikut:

1. Uji Validitas

Validitas adalah suatu ukuran yang menunjukkan tingkat-tingkat kevalidan sesuatu instrumen (Arikunto, 2006:168). Suatu instrumen yang valid atau sahih mempunyai validitas tinggi. Sebaliknya instrumen yang kurang valid berarti memiliki validitas rendah.

Berdasarkan hasil perhitungan niali $\mathrm{r}$ hitung dengan program SPSS, maka perbandingan nilai r-hitung dengan niali $\mathrm{r}$ tabel dapat dilihat pada Tabel.4 berikut ini:

Tabel. 4

Perhitungan Nilai Sig. (2-Tailed) Indeks Kepuasan Masyarakat

\begin{tabular}{|c|c|c|c|}
\hline No & $\begin{array}{l}\text { INDEKS KEPUASAN } \\
\text { MASYARAKAT }\end{array}$ & $\begin{array}{l}\text { NILAI SIG. } \\
\text { (2-TAILED) }\end{array}$ & KETERANGAN \\
\hline 1 & Pernyataan Pertama & .028 & Valid \\
\hline 2 & Pernyataan Kedua & .000 & Valid \\
\hline 3 & Pernyataan Ketiga & .000 & Valid \\
\hline 4 & Pernyataan Kempat & .000 & Valid \\
\hline 5 & Pernyataan Kelima & .000 & Valid \\
\hline 6 & Pernyataan Keenam & .000 & Valid \\
\hline 7 & Pernyataan Ketujuh & .000 & Valid \\
\hline 8 & Pernyataan Kedelapan & .000 & Valid \\
\hline 9 & Pernyataan Kesembilan & .000 & Valid \\
\hline 10 & Pernyataan Kesepuluh & .000 & Valid \\
\hline 11 & Pernyataan Kesebelas & .000 & Valid \\
\hline 12 & Pernyataan Keduabelas & .000 & Valid \\
\hline 13 & Pernyataan Ketigabelas & .000 & Valid \\
\hline 14 & Pernyataan Kempatbelas & .000 & Valid \\
\hline
\end{tabular}

Sumber: Data primer yang diolah, 2016

Berdasarkan Tabel 4 tersebut di atas, menunjukkan bahwa untuk 14 unsur yang berhubungan dengan indeks kepuasan masyarakat semuanya lulus dari hasil uji validitas karena nilai Sig. (2-Tailed)nya lebih kecil dari $\alpha=5 \%$ (tingkat kepercayaan 95\%). Dengan demikian dapat disimpulkan bahwa seluruh pernyataan unsur indeks kepuasan masyarakat dinyatakan valid, sehingga dapat digunakan sebagai alat ukur dalam penelitian.

\section{Uji Realibilitas}

\section{Menurut Sugiono}

(2009:172), Instrumen yang reliabel adalah instrumen yang bila digunakan beberapa kali untuk memngukur objek yang sama, akan menghasilkan data yang sama.

Berdasarkan hasil pengolahan data dengan menggunakan Program SPSS versi 15,0 diperoleh hasil sebagaimana Tabel 6 berikut ini:

Tabel 6

\section{Hasil Uji Reliabilitas IKM}

\begin{tabular}{|c|l|c|c|c|}
\hline No & Uraian & $\begin{array}{c}\text { Cronbach's } \\
\text { Alpha }\end{array}$ & $\begin{array}{c}\text { Alpha } \\
\text { Pembanding }\end{array}$ & Hasil \\
\hline 1 & $\begin{array}{l}\text { Indeks } \\
\text { Kepuasan } \\
\text { Masyarakat }\end{array}$ & 0,797 & $.>0,60$ & Reliabel \\
\hline
\end{tabular}

Sumber: Data primer yang diolah, 2016

Berdasarkan Tabel 6 tersebut di atas, diketahui bahwa nilai setelah semua indikator Alpha Cronbach lebih besar dari Alpha Pembanding, sehingga indeks kepuasan masyarakat dapat dikatakan reliabel sebagai alat ukur dalam penelitian selanjutnya.

\subsection{Analisis Indeks Kepuasan Masyarakat \\ Indeks Kepuasan Masyarakat} digunakan untuk mengetahui bagaimana tanggapan masyarakat pengguna layanan ini akan pelayanan yang telah diberikan kepadanya. Indeks ini digunakan sebagai tolok ukur dari kualitas pelayanan Pukesmas Sungai Lilin Kecamatan Sungai Lilin, apakah sudah memenuhi standar 
pelayanan minimal yang telah diisyaratkan oleh pemerintah. Kepuasan masyarakat dapat diketahui dengan melihat kualitas pelayanan dari masing-masing indikator yang telah ditentukan, dimulai dengan menganalisis indikator yang ada.

Setiap item indikator dianalisis, kemudian skor item indikator tersebut dicari rata-ratanya untuk menganalisis kualitas dari kinerja setiap indikator baru kemudian total skor keseluruhan dari 14 indikator yang ada dalam penelitian ini dicari rata-ratanya untuk menentukan indeks kepuasan masyarakat.
Berdasarkan hasil penelitian dan setelah dilakukan tabulasi data maka diperoleh nilai indeks kepuasan masyarakat per unsur pelayanan pada Puskesmas Sungai Lilin Kecamatan S Lilin sebagai berikut: bahwa mayoritas responden menyatakan kondisi per pelayanan indikator secara realisasi di Puskesmas Sungai Lilin sudah baik, hal ini terbukti dari 140 responden yang diteliti memberikan penilaian yang bisa dilihat pada tabel 7 , ini sudah sesuai dengan harapan masyarakat.

Tabel 7

Nilai Per Unsur Pelayanan Hasil Analisa Indeks Kepuasan Masyarakat

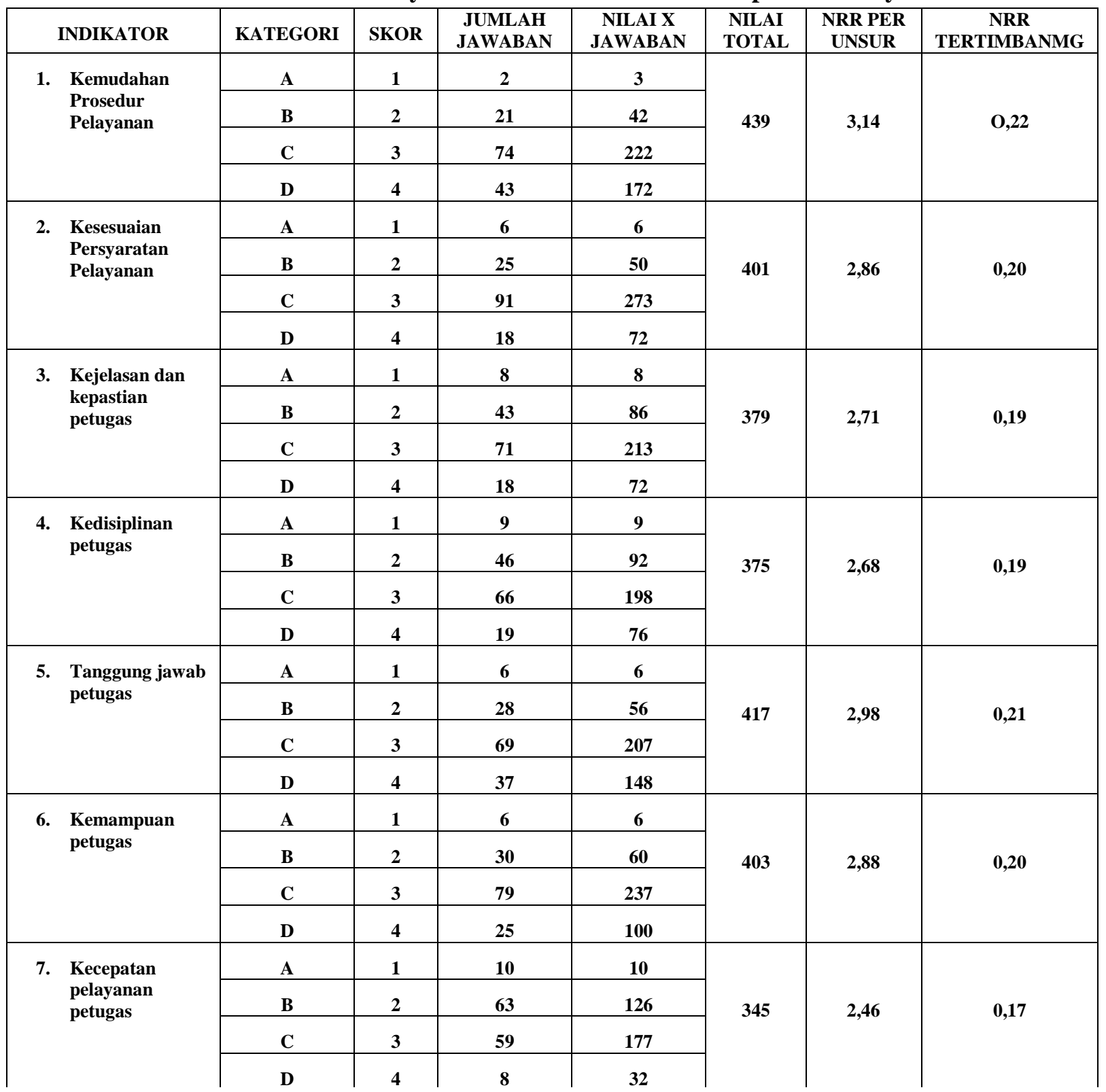




\begin{tabular}{|c|c|c|c|c|c|c|c|c|}
\hline & \multirow{4}{*}{$\begin{array}{l}\text { Keadilan untuk } \\
\text { mendapatkan } \\
\text { palayanan }\end{array}$} & $\mathbf{A}$ & 1 & 5 & 5 & \multirow{4}{*}{423} & \multirow{4}{*}{3.02} & \multirow{4}{*}{0,21} \\
\hline & & B & 2 & 20 & 40 & & & \\
\hline & & C & 3 & 82 & 246 & & & \\
\hline & & D & 4 & 33 & 132 & & & \\
\hline \multirow[t]{4}{*}{2.} & \multirow{4}{*}{$\begin{array}{l}\text { Kesopanan dan } \\
\text { keramahan } \\
\text { petugas }\end{array}$} & $\mathbf{A}$ & 1 & 4 & 4 & \multirow{4}{*}{395} & \multirow{4}{*}{2,82} & \multirow{4}{*}{0,20} \\
\hline & & B & 2 & 40 & 80 & & & \\
\hline & & $\mathbf{C}$ & 3 & 73 & 219 & & & \\
\hline & & D & 4 & 23 & 92 & & & \\
\hline \multirow[t]{4}{*}{3.} & \multirow{4}{*}{$\begin{array}{l}\text { Kewajaran } \\
\text { biaya pelayanan }\end{array}$} & $\mathbf{A}$ & 1 & 10 & 10 & \multirow{4}{*}{381} & \multirow{4}{*}{2,72} & \multirow{4}{*}{0,19} \\
\hline & & B & 2 & 38 & 76 & & & \\
\hline & & C & 3 & 73 & 219 & & & \\
\hline & & D & 4 & 19 & 76 & & & \\
\hline \multirow[t]{4}{*}{4.} & \multirow{4}{*}{$\begin{array}{l}\text { Kesuaian biaya } \\
\text { yang dibayarkan } \\
\text { dengan biaya } \\
\text { yang ditetapkan }\end{array}$} & $\mathbf{A}$ & 1 & 9 & 9 & \multirow{4}{*}{391} & \multirow{4}{*}{2,79} & \multirow{4}{*}{0,20} \\
\hline & & B & 2 & 37 & 74 & & & \\
\hline & & $\mathbf{C}$ & 3 & 68 & 204 & & & \\
\hline & & D & 4 & 26 & 104 & & & \\
\hline \multirow[t]{4}{*}{5.} & \multirow{4}{*}{$\begin{array}{l}\text { Ketepatan } \\
\text { pelaksanaan } \\
\text { terhadap jadwal } \\
\text { waktu } \\
\text { pelayanan }\end{array}$} & $\mathbf{A}$ & 1 & 52 & 52 & \multirow{4}{*}{268} & \multirow{4}{*}{1,91} & \multirow{4}{*}{0,14} \\
\hline & & B & 2 & 51 & 102 & & & \\
\hline & & $\mathbf{C}$ & 3 & 34 & 102 & & & \\
\hline & & D & 4 & 3 & 12 & & & \\
\hline \multirow[t]{4}{*}{6.} & \multirow{4}{*}{$\begin{array}{l}\text { Kenyamanan di } \\
\text { lingkungan unit } \\
\text { pelayanan }\end{array}$} & $\mathbf{A}$ & 1 & 9 & 9 & \multirow{4}{*}{395} & \multirow{4}{*}{2,82} & \multirow{4}{*}{0,20} \\
\hline & & B & 2 & 29 & 58 & & & \\
\hline & & C & 3 & 80 & 240 & & & \\
\hline & & D & 4 & 22 & 88 & & & \\
\hline 7. & Keamanan unit & $\mathbf{A}$ & 1 & 9 & 9 & & & \\
\hline & pelayanan & B & 2 & 22 & 44 & 423 & 3,02 & 0,21 \\
\hline & & $\mathbf{C}$ & 3 & 76 & 228 & & & \\
\hline & & D & 4 & 33 & 142 & & & \\
\hline JUM & LAH NRR IKN & RTI & & & & & & 2,73 \\
\hline JUM & ILAH NILAI KC & RS & & $\mathbf{I} \mathbf{T}$ & NG & & & 68,25 \\
\hline
\end{tabular}

Sumber: Data primer yang diolah, 2016

Selanjutnya, hasil nilai Konversi Indeks Kepuasan Masyarakat (IKM) Puskesmas Sungai Lilin Kecamatan Sungai Lilin Kabupaten Musi Banyuasin, disesuaikan dengan kategorisasi mutu pelayanan berdasarkan indeks vang dituniukkan pada Tabel 8 sebagai berikut:

Tabel. 8

Kategorisasi Mutu Pelayanan

\begin{tabular}{|c|c|c|c|}
\hline $\begin{array}{c}\text { Nilai Interval } \\
\text { IKM }\end{array}$ & $\begin{array}{c}\text { Nilai Interval Konversi } \\
\text { IKM }\end{array}$ & $\begin{array}{c}\text { Mutu } \\
\text { Pelayanan }\end{array}$ & $\begin{array}{c}\text { Kinerja Unit } \\
\text { Pelayanan }\end{array}$ \\
\hline $\mathbf{1 , 0 0}-\mathbf{1 , 7 5}$ & $\mathbf{2 5 , 0 0}-\mathbf{4 3 , 7 5}$ & D & TIDAK BAIK \\
\hline $\mathbf{1 , 7 6}-\mathbf{2 , 5 0}$ & $\mathbf{4 3 , 7 6}-\mathbf{6 2 , 5 0}$ & C & KURANG BAIK \\
\hline $\mathbf{2 , 5 1}-\mathbf{3 , 2 5}$ & $\mathbf{6 2 , 5 1}-\mathbf{8 1 , 2 5}$ & B & BAIK \\
\hline $\mathbf{3 , 2 6}-\mathbf{4 , 0 0}$ & $\mathbf{8 1 , 2 6}-\mathbf{1 0 0 , 0 0}$ & A & SANGAT BAIK \\
\hline
\end{tabular}

Sumber: KEPMENPAN Nomor KEP/25/M.PAN/2/2004 
Berdasarkan kategorisasi mutu Musi Banyuasin berada dalam mutu pelayanan pada tabel 8 di atas, maka Puskesmas Sungai Lilin Kecamatan S. Lilin Kabupaten Musi Banyuasin memperoleh hasil Konversi IKM sebesar 68,25, berarti kinerja unit pelayanan Pukesmas Sungai Lilin Kecamatan Sungai Lilin kabupaten pelayanan "B" dengan kategori "BAIK" Apabila Nilai Indeks Kepuasan Masyarakat dilihat dari masing-masing per unsur, maka nilai IKM pada Puskesmas Sungai Lilin dapat dilihat pada Tabel 9 sebagai berikut:

Tabel 9

Indeks Kepuasan Masyarakat Perunsur Pelayanan Puskesmas S Lilin Kecamatan S lilin

\begin{tabular}{|c|c|c|c|c|c|}
\hline $\mathrm{NO}$ & UNSUR PELAYANAN & $\begin{array}{l}\text { Nilai } \\
\text { IKM }\end{array}$ & $\begin{array}{c}\text { Nilai } \\
\text { Konversi IKM } \\
\end{array}$ & $\begin{array}{c}\text { Mutu } \\
\text { Pelayanan } \\
\end{array}$ & Kinerja \\
\hline 1 & Prosedur pelayanan & 3,14 & 78,5 & $\mathrm{~B}$ & Baik \\
\hline 2 & Persyaratan pelayanan & 2,86 & 71,5 & $\mathrm{~B}$ & Baik \\
\hline 3 & Kejelasan petugas pelayanan & 2,71 & 67,75 & $\mathrm{~B}$ & Baik \\
\hline 4 & Kedisiplinan petugas & 2,68 & 67,0 & $\mathrm{~B}$ & Baik \\
\hline 5 & Tanggung jawab petugas & 2,98 & 74,5 & $\mathrm{~B}$ & Baik \\
\hline 6 & Kemampuan petugas & 2,88 & 72,0 & $\mathrm{~B}$ & Baik \\
\hline 7 & Kecepatan pelayanan & 2,46 & 61,5 & $\mathrm{~B}$ & Baik \\
\hline 8 & Keadilan mendapatkan pelayanan & 3,02 & 75,5 & $\mathrm{~B}$ & Baik \\
\hline 9 & Kesopanan dan keramahan petugas & 2,82 & & & Baik \\
\hline 10 & Kewajaran biaya pelayanan & 2,72 & & & Baik \\
\hline 11 & Kepastian biaya pelayanan & 2,79 & 69,75 & $\mathrm{~B}$ & Baik \\
\hline 12 & Kepastian jadwal pelayanan & 1,91 & 47,75 & $\mathrm{C}$ & Kurang Baik \\
\hline 13 & Kenyamanan unit lingkungan & 2,82 & 70,5 & $\mathrm{~B}$ & Baik \\
\hline 14 & Keamanan unit pelayanan & 3,02 & 70,5 & $\mathrm{~B}$ & Baik \\
\hline & & & 68,0 & $\mathrm{~B}$ & \\
\hline
\end{tabular}

\section{Kesimpulan dan Saran}

\subsection{Kesimpulan}

Berdasarkan hasil perhitungan dan analisis di atas maka dapat diambil kesimpulan sebagai berikut:

1. Angka indeks IKM sebesar 68,25 yang berada pada interval 62,51 81,25, menunjukkan kualitas pelayanan publik berada pada tingkat mutu "B". Hal ini berarti kinerja pelayanan Puskesmas Sungai Lilin Kecamatan Sungai Lilin pada tahun 2016 secara keseluruhan termasuk dalam kategori "Baik". Dan berada pada kategori mutu baik, unsur dengan nilai IKM antara 61,5 - 69,75 yaitu unsur kecepatan pelayanan, kedisiplinan petugas, kejelasan petugas, kewajaran biaya pelayanan, dan kepastian biaya pelayanan berada pada kategori baik, dan kategori kinerja baik, sedangkan unsur dengan indeks terendah yaitu unsur kepastian jadwal pelayanan dengan nilai IKM sebesar 47,75 berada pada tingkat mutu baik, dan kategori kinerja baik.

\subsection{Saran}

Berdasarkan kesimpulan di atas, maka penulis menyarankan kepada Pukesmas 
Sungai Lilin Kecamatan Sungai Lilin Kabupaten Musi Banyuasin yaitu sebagai berikut:

1. Pelayanan Pukesmas Sungai Lilin tergolong baik. Untuk ke depan maka, pelayanan yang diberikan.minimal dipertahankan atau jika mungkin dapat terus ditingkatkan, menjadi lebih baik lagi meningkat menjadi kategori kinerja sangat baik.

2. Unsur prosedur pelayanan dengan nilai IKM tertinggi perlu untuk tetap dipertahankan dengan membuat brosur/daftar prosedur agar mudah diketahui secara jelas oleh masyarakat.

3. Kepastian jadwal pelayanan merupakan unsur dengan nilai IKM terendah dibandingkan dengan unsur pelayanan lainnya, diduga karena kurang petugas maka perlu menambah petugas pelayanan agar proses pelayanan semakin baik dan cepat.

4. Jangka waktu pelayanan yang diberikan kepada masyarakat diupayakan untuk lebih baik dan lebih cepat dibandingkan dengan standar waktu pelayanan yanmg telah ditentukan.

5. Informasi pelayanan dibuat baku dalam Papan Informasi mengenai alur pelayanan dari prosedur, persyaratan, kepastian jadwal, waktu dan biaya pelayanan pada setiap jenis pelayanan yang dapat dilihat langsung oleh masyarakat.

\section{DAFTAR PUSTAKA}

Arief, Muhtosim. 2007. Pemasaran Jasa dan Kualitas Pelayanan. Malang: Bayumedia Publishing.
Arikunto, Suharsini 2009. Prosedur Penelitian Suatu Pendekatan Praktik. Edisi Revisi 6, Jakarta: Rineka Cipta.

Keputusan Menteri Pendayaan Aparatur Negara Nomor 25 /KEP//M. PAN/2/2004: tentang Pedoman Umum Penyusunan Indeks Kepuasan Masyakat.

Keputusan Menteri Pendayaan Aparatur Negara Nomor 63/KEP/M.PAN/7/2003: tentang Pedoman Umum Penyusunan Indeks Kepuasan Publik.

Moenir, H.A.S., 2000, Manajemen Pelayanan Umum di Indonesia, Bumi Aksara, Jakarta

Hardi, Utomo. 2015. Analisis Indeks Kepuasan Masyarakat (IKM) Pada Pelayanan Publik Di Puskesmas Kalicacing Kota Salatiga. Salatiga. Jurnal Among Makarti Vol.8 No.15, Juli 2015.

Saladdin Wirawan Effendy. 2011.Analisis Indek Kepuasan Masyarakat Pada Badan Perizinan dan Penanaman Modal Kabupaten Ogan Komering Ilir. Palembang . OCPUS: Jurnal Akuntansi Bisnis dan Informatika.Volume 3 No. 2, Juli Desember 2011

Sugiyono. 2005. Statistika untuk Penelitian. Bandung: CV. Alfabeta Sugiyono. 2009. Metode Penelitian Kuantitatif dan Kualitatif. Bandung: CV. Alfabeta

Sugiyono. 2010. Statistika untuk Penelitian. Bandung: CV. Alfabeta 